\title{
Sustentabilidade nas Construções da Copa 2014, em Curitiba
}

\author{
Sustainability on Constructions of the World Cup 2014, in \\ Curitiba
}

\author{
Sileide France Turan Salvador ${ }^{6}$ \\ Ana Helena Corrêa de Freitas Gil \\ Eloy Fassi Casagrande Júnior
}

\section{Resumo}

Esse trabalho busca destacar a necessidade de aprofundar o conhecimento das relações que envolvem políticas públicas, sua avaliação e a sustentabilidade dinâmica. Portanto, conhecer o processo permite 0 entendimento dos fatores internos e externo que influenciam e/ou modificam o as estratégias de sustentabilidade na Copa do Mundo 2014, em Curitiba. O estudo busca analisar a função social da construção sustentável na Copa 2014 e a conectividade urbana e econômica e social. Apresenta as características desejáveis em uma construção sustentável.

Palavras-chave: Sustentabilidade; Políticas Públicas; Copa do Mundo 2014; Curitiba.

${ }^{6}$ Sileide France Turan Salvador: Mestre em Tecnologia, professora do Instituto Federal do Paraná - IFPR - Campus Curitiba- Brasil. Possui Mestrado em Tecnologia pela Universidade Tecnológica Federal do Paraná, UTFPR (2010), PósGraduação em Especialização em Formação de Professores em EAD pela Universidade Federal do Paraná-UFPR (2001) e Graduação em Licenciatura em Letras Português - Inglês pela Universidade Tuiuti do Paraná-UTP (1998) pela Universidade Federal do Paraná. É professora do Instituto Federal do Paraná, atuando no ensino de Língua Inglesa para o Ensino Médio. E-mail: sileide.salvador@ifpr.edu.br

Ana Helena Corrêa de Freitas Gil: Professora Doutora em Geografia do Instituto Federal do Paraná - Campus Curitiba - Brasil. Possui Graduação em Estudos Sociais e Educação Moral e Cívica pela Faculdade de Ciências Letras e Educação de Presidente Prudente (1985), Graduação em Geografia pela Faculdade de Ciências Humanas e Sociais de Curitiba (1991), Especialização em Geografia Física (UNICENTRO -1991) e Especialização em Magistério Superior (TUIUTI- 1989), Mestrado em Geografia pela Universidade Federal do Paraná (2003) com o tema: Shopping Centers em Curitiba: Novos espaços de consumo e lazer. Doutorado em Geografia pela UFPR (2011) na linha de pesquisa: Território, Cultura e Representação com a pesquisa sobre Palcos do Cotidiano: O bairro urbano como espaço de ação e da expressão teatral, Também é autora de livros didáticos do Ensino Fundamental pela Base Editora. E-mail: ana.gil@ifpr.edu.com.

Eloy Fassi Casagrande Júnior: Professor Doutor do PPGTE/UTFPR- Campus Curitiba, concluiu o doutorado em Engenharia de Recursos Minerais e Meio Ambiente pela Universidade de Nottingham em 1996 e o Pós-Doutorado no Instituto Superior Técnico (IST-Portugal) em 2007. Atualmente é Coordenador do Escritório Verde e professor do Departamento Acadêmico de Construção Civil e da PósGraduação da Universidade Tecnológica Federal do Paraná. E-mail: eloy.casagrande@gmail.com. 


\section{Abstract}

This work aims to emphasize the need to deepen the understanding of the relationships that involve public policy, its dynamics and sustainability assessment. Therefore, knowing the process allows an understanding of internal and external factors that influence and / or modify the sustainability strategies in the World Cup 2014, in Curitiba. The study analyzes the social role of sustainable construction in the 2014 World Cup and urban connectivity and economic and social development. It presents the characteristics desirable in a sustainable building.

Keyword: Sustainability, Public Policy, World Cup 2014, Curitiba.

\section{Introdução}

A sustentabilidade, como ideia central do desenvolvimento sustentável, integra espaços, períodos e contextos num processo contínuo (JIMÉNEZ HERRERO, 2000). Na perspectiva de um megaevento sustentável, a Copa 2014, integra conhecimentos, ações, agentes e ferramentas de mensuração eficazes. Esse processo está composto por uma meta organizacional e ações objetivas que interligam políticas públicas, sustentabilidade e sociedade. Busca-se, nesta estratégia, um equilíbrio sistêmico composto pelas interações entre os sistemas envolvidos na organização do megaevento.

Seguindo a proposta de Martins e Theóphilo (2007), desenvolve-se, neste artigo, uma pesquisa básica, no qual o problema é apresentado numa perspectiva qualitativa, com objetivos e estratégias analisadas a partir de um ponto de vista exploratório e bibliográfico, quando são adotados os procedimentos abordados, após densa pesquisa.

O Brasil se organiza para sediar a Copa 2014, que se propõe a ser um evento sustentável, porém, como analisar essa implementação e estruturação? Esse trabalho que considera os impactos da Copa do Mundo de 2014, em Curitiba, tem como objetivo verificar as estratégias utilizadas nas construções relacionadas com a Copa 2014, identificando os conceitos de sustentabilidade desenvolvidos em Curitiba. O contexto do trabalho perpassa pelos pressupostos da responsabilidade na conservação do meio no qual se vive e na realidade construída de que pensar globalmente envolve agir localmente. $\bigcirc$ estudo também ressalta ações de sustentabilidade que já possuem certa visibilidade social, objetivado sinalizar as várias possiblidades de divulgação dessas práticas, que atuam nas seguintes categorias: a conservação de energia e mudanças climáticas, água, gestão integrada de resíduos, transporte, mobilidade e acesso, paisagem e biodiversidade, edifícios verdes e estilo de vida sustentáveis, além da construção sustentável. Como recurso metodológico de pesquisa básica qualitativa e análise (MARTINS; THEÓPHILO, 2007), o artigo apresenta aspectos da Copa 2014 que são característicos de megaeventos esportivos e da sustentabilidade.

Torna-se primordial, nessa primeira fase, apresentar uma análise histórico-processual das políticas públicas que norteam a implementação 
das estratégias de sustentabilidade nas Copas anteriores e que orientam a Copa 2014, em Curitiba, desenvolve-se, dessa forma, uma visão holística sobre essa política pública no que diz respeito à comunidade local, impactos, gestão e sustentabilidade, baseada em análise documental, avaliação do processo, dos indicadores, dos impactos e legados sustentáveis advindos do megaevento na cidade (GELINSKI; SEIBEL, 2008). Há seis áreas que deveriam ser abarcadas para que a Copa seja realizada em algum país estão elencadas no United Nations Environment Programme (UNEP). São elas: mudanças climáticas, desastres e conflitos, manejo de ecossistema, governança do meio ambiente, substâncias perigosas e eficiência do uso de recursos naturais (ERNST; YOUNG, 2010, p.18).

Os eventos sustentáveis apresentam três temas que norteiam o desafio do estabelecimento da sustentabilidade em suas estruturas. Esses temas compõem o triple bottom line ou tripé da sustentabilidade: economia, sociedade e meio-ambiente. Portanto, um evento sustentável, precisa administrar seus riscos, em um conceito que impeça a degradação do ambiente, gerando, simultaneamente riquezas que atinjam diversas camadas da comunidade, garantindo que as futuras populações e gerações sejam beneficamente afetadas por suas ações. As práticas adotadas devem: proteger, reciclar, reutilizar e usar de maneira responsável os recursos naturais disponíveis; agregar valor à economia local e educar os participantes do evento sobre os benefícios da sustentabilidade, deixando um legado futuro que ultrapasse o tempo em que o evento durar. Essas práticas devem ser o marco de uma cultura sustentável (MUSGRAVE, 2009).

De acordo com um ensaio preliminar de indicadores feito pela Ernst e Young (2010), denominado "Brasil Sustentável: Impactos socioeconômicos da Copa do Mundo de 2014" foram priorizados sete passos para a Copa Verde, identificados conforme o padrão preestabelecido de responsabilidade socioambiental dos estados e áreas prioritárias do Green Goal e a realidade particular brasileira. Segundo o documento, os sete passos para o sucesso da Copa Verde são: conservação de energia e mudanças climáticas; água; gestão integrada de resíduos; transporte, mobilidade e acesso; paisagem e biodiversidade; edifícios verdes e estilos de vida sustentável; e, construção sustentável. Assim sendo, Curitiba, enquanto capital escolhida precisa desenvolver projetos caracterizados pela sustentabilidade ambiental e econômica.

Além desta seção introdutória, o artigo segue a seguinte estrutura: arcabouço teórico explicitando os seguintes temas - Mega Eventos e A Sustentabilidade, Construção Civil e a Sustentabilidade. Inseridos no corpo textual das seções são mencionadas algumas ações da construção sustentável. Posteriormente, são apresentadas as considerações finais, onde estão estabelecidas as relações entre os pressupostos teóricos, as ações e os objetivos propostos inicialmente. 


\section{Mega Eventos e a sustentabilidade}

Em 1987, a segunda conferência da Organização das Nações Unidas (ONU) para discutir os problemas socioambientais globais, lançou o Relatório Brundtland - intitulado também como Nosso Futuro Comum (Our Common Future), onde se oficializa o termo "desenvolvimento sustentável", torna-se importante destacar que, na época, o recorte principal tratava da sustentabilidade como 0 atendimento das necessidades do presente sem comprometer a possibilidade de que as gerações futuras atendam as suas próprias necessidades. Surgiram, então, novas diretrizes, importantes conferências e documentos como o Protocolo de Quioto, em 1997. Quioto alertava com mais rigidez para as consequências do efeito estufa e do aquecimento global.

Analisando os componentes inter-relacionados e que necessitam passar pela revolução da sustentabilidade, destacam-se: a proteção da biodiversidade que envolve as espécies, os genes, os sistemas naturais, os processos químicos e biológicos, componentes da Terra. A eficiência, enquanto capacidade de planejar estratégias para minimizar o desperdício de recursos de ordem material e energético, reduzindo a dependência de combustíveis fósseis não renováveis e, simultaneamente, otimizando a relação com formas de energias renováveis. Também como um componente enquadra-se a prevenção da poluição ou degradação ambiental, a contenção do uso e produtos químicos nocivos e aspectos econômicos e políticos que recompensam as estratégias benéficas ao meio ambiente e desencorajam os comportamentos prejudiciais. Considerando essa concepção de revolução sustentável, as interconexões são legados de curto, médio e longo prazo com componentes mensuráveis e imensuráveis.

Inserido no conceito de Copa Sustentável, o megaevento de 2014 que ocorrerá no Brasil, destaca pressupostos de tecnologia, sustentabilidade e inovação. Segundo Ernst e Young (2010, p. 16) os megaeventos como a Copa do Mundo costumam constituir-se em modelos para ações futuras e adoções de políticas nacionais. Sente-se a necessidade de agregar, na análise dos impactos socioeconômicos, os aspectos ambientais e de sustentabilidade envolvidos no processo. O conceito de legado aparece em 1956, no contexto da Olimpíada de Melbourne, como conexão entre megaeventos e as políticas públicas de desenvolvimento (FUSSEY; CLAVELL, 2011).

Numa retrospectiva histórica, importa recordar que foi em julho de 2010, no decorrer da última Copa do Mundo organizada pela Fédération Internationale de Football Association (FIFA), e realizada na África do Sul, que o Brasil lançou, oficialmente, a "Jornada para a Copa de 2014", através de seu então presidente Luiz Inácio Lula da Silva. Ele destacou, em seu discurso, a prioridade de que o futuro megaevento fosse uma "Copa Verde" e que se mostrasse ao mundo o compromisso brasileiro no que tange à sustentabilidade ambiental.

Essa iniciativa do governo brasileiro traz consigo desafios e oportunidades para o país-anfitrião. Alcançar-se um bom desempenho na promoção do desenvolvimento sustentável através desse tipo de competição global significa ter que 
contribuir para a redução de custos sociais e ambientais, ineficiências e desperdícios, além de colaborar para maior integração entre os vários atores da sociedade e o desenvolvimento contínuo das pessoas, das comunidades e dos relacionamentos entre a sociedade e o meio ambiente. "Para os governos, o sucesso da Copa poderá ser medido pelo aumento da arrecadação e geração de riqueza, bem como pelos ganhos de imagem e visibilidade que possam depois ser revertidos em capital político" (ERNST \& YOUNG, FGV PROJETOS, 2010, p. 52-53).

Para lidar com este desafio, foi criada em maio de 2010 uma Câmara Temática Nacional de Meio Ambiente e Sustentabilidade (CTMAS) sob a coordenação dos Ministérios do Esporte e do Meio Ambiente. Seguiu-se a criação de Câmaras Estaduais, sob as diretrizes da FIFA, para a Copa do Mundo 2014. Segundo Langone (2009), as principais diretrizes para o evento no Brasil, são:

. neutralizar suas emissões de gases de efeito estufa (GEE) e cooperar com o combate ao aquecimento global;

. promover a sustentabilidade ambiental com inclusão social;

. incentivar e alavancar negócios verdes;

. eficiência energética;

. valorizar e ajudar a promover e proteger a biodiversidade brasileira;

- construir estádios com sustentabilidade;

. utilizar a água de maneira racional;

. incentivar a mobilidade e circulação sustentáveis;

. incentivar o consumo de produtos orgânicos e/ou sustentáveis; e

. promover o ecoturismo nos biomas brasileiros.

Inovação, sustentabilidade e tecnologia são categorias que, vinculadas a um megaevento como a Copa do Mundo de 2014, podem redefinir o papel Estado. Assim, refletindo-se em políticas públicas inovadoras que agreguem novas tecnologias conceituais, estruturas e operacionais (BELLEN, 2005). Para que as políticas públicas representem a forma mais democrática de adequação e estabelecimento do alicerce para a obtenção do crescimento sustentável, faz-se necessário que essas políticas apresentem um planejamento que integrem a sociedade, a conjunção de interesses econômicos, políticos, sociais e comerciais, necessitando caracterizar um autêntico processo democrático (SILVA; CASTRO RAULI, 2009).

Apresentando um breve histórico desse megaevento, vale registrar que, em 1872, ocorreu a primeira Copa do Mundo com jogos amistosos que ocorreram entre as comunidades britânicas. No ano de 1904, em maio, foi criada a FIFA - Federação Internacional da Associação do Futebol, essa instituição passou a traçar diretrizes para futuros eventos internacionais. $\mathrm{Na}$ ocasião, a FIFA registrava sete países associados: França, Bélgica, Dinamarca, Holanda, Espanha, Suécia e Suíça. Atualmente, são mais de 213, os países registrados e participantes da FIFA.

Em 2007 foi publicado pela FIFA, a $4^{\circ}$ Edição do Manual de Especificações Técnicas para Estádios de Futebol. Neste Manual constam exigências e pressupostos como: decisões de pré-construções referentes às 
dimensões mínimas e capacidade de público; orientação do campo, também esclarece questões como a área do jogo relativo ao tamanho, à grama, às arquibancadas; orientação das tribunas para mídia; diretrizes para segurança pública, conforto e hospitalidade; localização dos estacionamentos, vestiários e acessos; diretrizes referentes à energia e iluminação. Fornece orientações sobre o Green Goal, um programa focado na sustentabilidade, que destaca a necessidade da redução das emissões de $\mathrm{CO}_{2}$ em eventos.

Assim, é possível apresentar uma linha do tempo relacionando a Copa do Mundo e a aplicação das tecnologias de sustentabilidade. Com a chegada da sustentabilidade aos megaeventos, três abordagens se destacam: os aspectos sociais, econômicos e ambientais, num conceito includente, sem hierarquizações socioculturais e ao mesmo tempo, com propostas economicamente viáveis de mínimo impacto ao meio ambiente, com estímulos como o LEED - Leadership in Energy and Environmental Design, selo criado em 2000, pela U.S. Green Building Council (USGBC), uma organização sem fins lucrativos criada nos Estados Unidos e com representação em diversos países, se constitui no selo de certificação para edifícios sustentáveis e está sendo recomendado pela FIFA para que todos os estádios estejam aptos à adoção do mesmo. Sendo um selo de reconhecimento internacional, proporciona visibilidade mundial às técnicas sustentáveis e a eficiência dos estádios. A certificação pretende a busca por estratégias construtivas mais sustentáveis determinadas através da adoção de critérios como: localização, inovação e processo do projeto, eficiência no uso da água e no tratamento de esgoto, redução no consumo de energia com o uso de fontes renováveis, o uso de materiais e recursos e a qualidade do ambiente interno (LEED, 2009).

Em 2006, na Alemanha, foi apresentado pela FIFA o programa Green Goal, iniciativa inovadora que busca viabilizar a sustentabilidade ambiental do evento, servindo de modelo exemplo para os eventos subsequentes. As diretrizes do Green Goal encontram-se no caderno de encargos da FIFA. Abrangem a construção, a segurança e a hospitalidade. Seguidos pelo comitê organizador do país-sede, permite que o país receba a liberação que reifica a aptidão do país candidato para gerir a Copa do Mundo. O Green Goal destaca quatro áreas temáticas: água, resíduos, energia e transporte sobre as quais devem ser estabelecidas metas mensuráveis para neutralizar os impactos no clima global (FIFA, 2003). Segundo o Green Goal Legacy Report da Copa da Alemanha (2006), esse megaevento, destacou, com sucesso, pela primeira vez, o meio ambiente na pauta das Copas do Mundo. Como legado, a sustentabilidade passou a estar presente nos eventos esportivos, cabendo a cada país elaborar projetos no contexto da realidade local.

Para analisar se o processo para a execução da Copa 2014, em Curitiba - PR é viável, buscam-se os resultados de pressupostos, como: o mapeamento dos impactos e legados econômicos, sociais, culturais e seus efeitos temporais a curto, médio e longo prazo. Sob uma visão holística das políticas públicas adotadas, no que diz respeito à comunidade local, impactos, gestão e sustentabilidade. A investigação apresenta os arranjos para o Megaevento Copa do Mundo de 2014 em Curitiba, embasados em 
objetivos, inovação, tecnologia e sustentabilidade. Essas categorias são elementos diferencias na percepção da construção dos aspectos simbólicos, sociais, conceituais e políticos da Copa de 2014, em Curitiba (FREY, 2000).

Interpretando os aspectos conceituais, destaca-se a compreensão da tecnologia como técnica que ressalta aspectos deterministas, não focados nas relações com a sociedade. É o isolamento da ciência e da tecnologia. Outra corrente concebe a tecnologia como construto de reações sociais, e/ou concebe a ciência e tecnologia como pressuposto otimizador do desenvolvimento científico e tecnológico Ao explicitar as posições conceituais acerca da tecnologia, ciência e sociedade, vale esclarecer que na primeira abordagem se supõe a ciência e a tecnologia como categorias inexoráveis, com autonomia e caminho próprio, podendo ou não influenciar a modificar a sociedade de alguma forma. Para a segunda abordagem, o uso da ciência e tecnologia é socialmente determinado e tende a estabelecer reproduções nas relações sociais, inibindo a mudança social.

\section{Construção civil e a sustentabilidade}

O mundo ocidental vive um momento diferenciado no que diz respeito às mudanças de paradigma no universo da arquitetura e das construções com a busca da sustentabilidade. Busca-se, através de um sistema tecnológico inovador, caracterizar os novos edifícios com maior desempenho e autonomia.

$\mathrm{Na}$ perspectiva da sustentabilidade as construções respondem às complexidades que perpassam adequações climáticas e ambientais, segurança, estabilidade e conforto. Portanto, analisando as dimensões da sustentabilidade, pode-se considerar a seguinte figura: 


\section{Dimensões da sustentabilidade na construção}

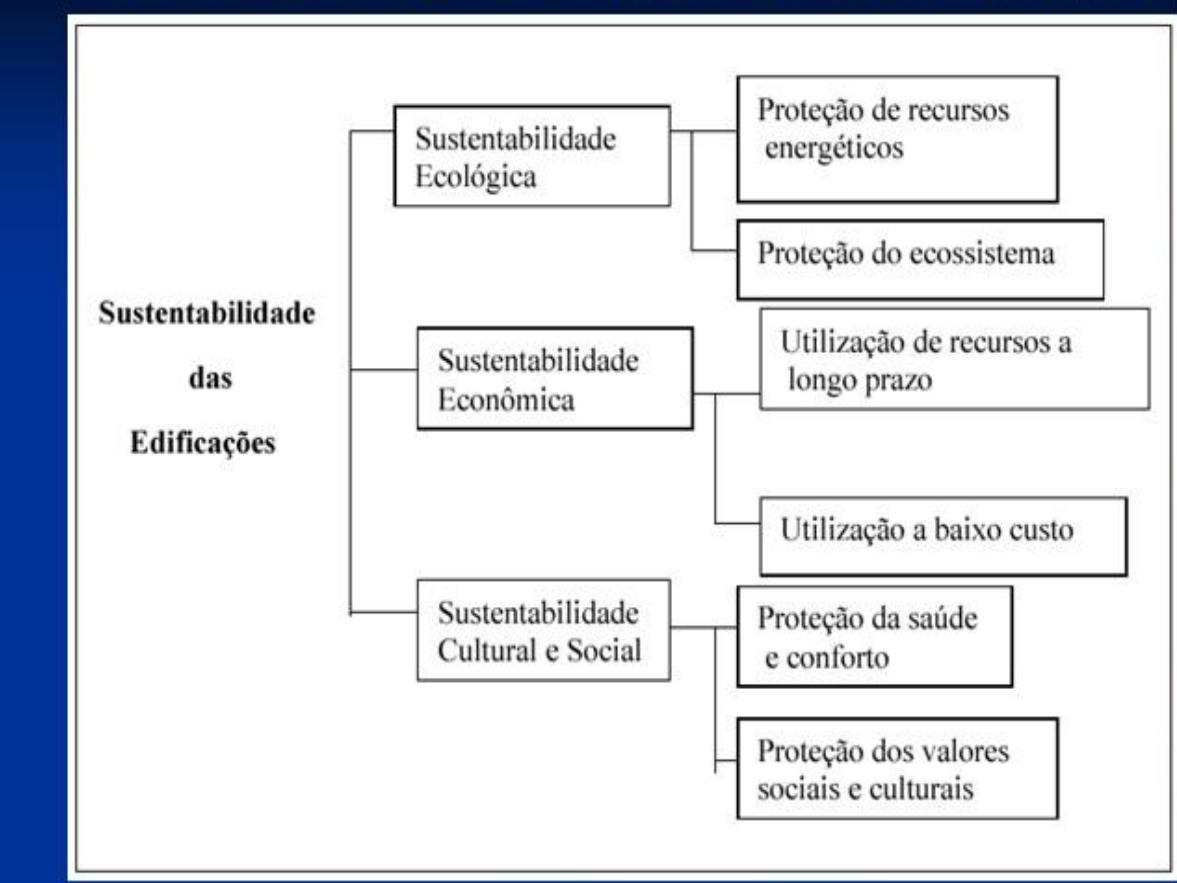

Fonte: CASAGRANDE JR, 2011

Os aspectos apresentados por Casagrande (2011) ressaltam a aproximação entre sustentabilidade, tecnologia $e$ inovação. A sustentabilidade nas edificações torna-se um mecanismo de estímulo da participação social para o desenvolvimento sustentável. Considerando as dimensões da sustentabilidade apresentadas, destacam-se, na sustentabilidade ecológica, aspectos como: a articulação de mecanismos que intensifiquem a pesquisa de tecnologias limpas com a consequente definição de estratégias e regras de adequação à proteção social. Também, através da limitação do uso de recursos não renováveis e/ou prejudiciais ao ambiente, promove-se, simultaneamente, a intensidade da poluição e a melhoria na capacidade dos recursos naturais.

Sobre a sustentabilidade econômica, importa compreender que essa dimensão promove uma melhoria na alocação, arranjos e gestão dos recursos numa abordagem eficiente de apropriação de investimentos privados e públicos, com a redução de custo sócio- ambiental. Vale ressaltar que as dimensões culturais e sociais perpassam tanto o respeito às tradições culturais de construção como introduzem modelos de modernização capazes de integrar soluções particulares de sustentabilidade que interagem com múltiplos sistemas de produção. Socialmente, essa dinâmica cria um desenvolvimento social plural, civilizatório, com base nas concepções do ser e não do ter, uma busca pela equidade. 
Nessa abordagem das dimensões da sustentabilidade, importa ter uma ideia, enfrentar o desafio da inovação, num gesto de pensamento criativo indutivo, numa conecção de novos meios de representar conceitos e práticas. Por isso, há considerações apresentando que [...] o engenheiro é hoje um herói da cultura pop. (FLORIDA, 2011, p. 209), pois esse profissional divulga as inovações tecnológicas e sustentáveis, buscando um melhor aproveitamento do processo construção e gestão dos bens públicos.

\begin{abstract}
Os bens públicos são aqueles cujo consumo/uso é indivisível ou "não rival". Em outras palavras, o seu consumo por parte de um indivíduo ou de um grupo social não prejudica o consumo do mesmo bem pelos demais integrantes da sociedade. Ou seja, todos se beneficiam da produção de bens públicos mesmo que eventualmente, alguns mais do que outros. São exemplos de bens públicos: bens tangíveis como as ruas ou a iluminação pública; e bens intangíveis como: justiça, segurança pública e defesa nacional. (GIAMBIAGI; ALÉM, 2011, p. 4)
\end{abstract}

Destacando possíveis critérios de sustentabilidade na construção, podem ser ressaltadas: o combate à poluição. Se as obras que geram emissão de detritos e materiais como: particulados (poeira, fumaça, fumo e névoa), gases poluentes, como $\circ \mathrm{CO}_{2}$ (gás carbono) e o $\mathrm{SO}_{2}$ (dióxido de enxofre), recebessem um tratamento específico desde sua terraplanagem até a execução, a ação dos poluentes afetaria minimamente o meio ambiente, do ar ao solo. O uso de técnicas simples como reaproveitamento e reciclagem e o armazenamento e adequação das formas de transporte. São técnicas simples como o rebaixamento das caçambas, a aspersão de água e construção de barreira física em caso de demolição e a lavagem dos pneus, evitam poeira e poluição advinda do canteiro de obras (RESENDE, 2007).

Impedir a erosão do solo que ocorre devido aos desgastes do terreno receptor das atividades de construção, também é uma das formas de prevenir a poluição. $O$ terreno natural contém matéria orgânica, nutrientes e a biodiversidade de micróbios e insetos, os quais controlam as enfermidades e pragas e conferem um equilíbrio na vida vegetal, além de regular a drenagem da água. Contudo, a ação das chuvas e o freqüente tráfego de veículos durante a execução da obra favorecem o enfraquecimento do solo causando o assoreamento e a perda de todo o equilíbrio vegetal contido no mesmo. Este fato pode restringir a viabilidade de plantios futuros, demandando o aumento de fertilizantes, irrigação e pesticidas, os quais, levados pela ação das chuvas, podem causar a poluição dos rios e lagos, próximos à edificação. De acordo com Daniela Corcuera, arquiteta auditora das certificações Acqua e Leed, uma forma eficaz de evitar esta poluição é o plantio de gramíneas adequadas e de rápido crescimento durante o processo de construção ajuda a impedir a erosão do solo e preserva as matérias orgânicas e os nutrientes naturais do solo, conservando o equilíbrio do habitat Podem ser utilizados elementos como cascas de árvores, pedriscos, palha ou mantas plásticas para cobrir e reter o solo (GUEDES, 2011). 
Atualmente existe o projeto de gerenciamento de resíduos em obras com grandes percentuais de entulhos, o qual é formalizado conforme a Resolução CONAMA $n^{\circ} 307$, formalizou os procedimento em grandes obras. Esse documento especifica os agentes: "o órgão público municipal (responsável pelo controle e fiscalização); os geradores de resíduos (responsáveis pela observância dos padrões previstos na legislação específica); e os transportadores (responsáveis pela destinação aos locais licenciados)." Cabe organizar estratégias de gestão em um organograma de atividades - "planejamento, implantação e monitoramento - que irá subsidiar o trabalho e todo o controle dos resíduos internos e externos à obra". Torna-se fundamental que a remoção e destinação dos resíduos seja monitorada e que os processos de coleta e armazenamento recebam tratamento especializado tanto no que tange ao material a ser reciclado como ao material que apresenta periculosidade, através de criteriosa triagem. Para a Resolução CONAMA n 307, são quatro as classes de resíduos da construção civil que podem ser consideradas: os agregados (componentes de pavimentações, componentes cerâmicos e peças prémoldadas); recicláveis com outras destinações (plásticos, papéis, metais, vidro, madeiras e outros); resíduos perigosos e não recicláveis. Através da reciclagem dos materiais evita-se e/ou deduz-se o desperdício e através da limpeza e organização do canteiro de obras, evita-se acidentes de trabalho.

Considerando o custo-benefício para a economia, o ambiente e a sociedade, a utilização de materiais regionais e reciclados é uma prática ser estimulada. Fatores que agregam valor a essa proposta: "o desenvolvimento regional devido à demanda de trabalho e à movimentação da economia local; dispensa o longo transporte para a entrega dos materiais, reduzindo a emissão de poluentes e $\mathrm{CO}_{2}$; reduz o desperdício; e, na maioria das vezes, é mais barato pela produção contígua ao local da obra". Para a certificação pelo Green Building Council Brasil (LEED), são aceitáveis situações como a distância entre o local da obra a ser construída e fonte fornecedora em um raio máximo de $800 \mathrm{~km}$ e também a utilização de no mínimo 10\% de materiais sustentáveis na edificação (LEED, 2009).

Ao conceber um edifício importa considerar as condições de conforto térmico, priorizando a ventilação natural, analisando a condição de conforto térmico diante de diversas funções e atividades desenvolvidas pelo grupo humano que disporá da construção. Desde condições climáticas, variações metabólicas dos indivíduos até mutações de temperatura e umidade. Para Frota e Schiffer (1999, p. 124), "A ventilação natural é o deslocamento do ar através do edifício, através de aberturas, umas funcionando como entrada e outras, como saída". Também natural, devem ser as entradas de iluminação no ambiente. Ao priorizar as luzes naturais e bem planejar o sistema de iluminação artificial, considerando fatores como: cores claras, refletores, varações de intensidade, painéis fotovoltaicos e concepção de circuitos autônomos são estratégias de eficácia da sustentabilidade operacionalizada.

Há duas categorias que devem ser balizadas na construção sustentável: a gestão da utilização da água, com práticas sustentáveis pode valer-se de dispositivos reguladores, mecanismos controladores que permitem o controle da vazão da água, duchas e torneiras hidromecânicas, 
bacias sanitárias com caixas acopladas e/ou acionamento de descarga com sensor de presença (FGV, 2010). Além dos impactos causados por esses mecanismos, é possível planejar a reutilização da água pluvial na construção, através de telhados e pátios adequados. Finalizando, importa destacar a questão da acessibilidade tanto na esfera da construção em si como aos possíveis meios de transportes, que devem incluir as diversas as mais diversas categorias, conferindo agilidade às dinâmicas do ambiente construído.

Infelizmente são mínimos os registros das práticas sustentáveis para a Copa 2014, em Curitiba. A obra com práticas sustentáveis para a Copa 2014 da qual há registro refere-se à Arena da Baixada, que investiu no exterior do edifício, revestindo-o com policarbonato, buscando melhorar a climatização dos espaços internos. Para os responsáveis pelo projeto, a ideia gerará uma economia de $30 \%$ no sistema de ar-condicionado em relação aos modelos convencionais. No aspecto da destinação de materiais de construção, a mídia indica que todos os estádios-sedes dos jogos da Copa do Mundo de 2014, estão buscando a sustentabilidade no que se refere às sobras dos materiais, que, normalmente, encheriam os aterros $e$ agora passaram a ser reaproveitados. Também há registros de que as 12 sedes terão reservatórios de água de chuva, que serão utilizadas nas descargas dos sanitários, irrigação do gramado e jardins, limpeza das áreas externas, entre outros. As estratégias articuladas pela Arena da Baixada visando o uso racional da água, a redução de seu consumo e o estímulo à adoção de novas atitudes e comportamentos não estão claras e definidas. (EcoDesenvolvimento.org.maio/2012). Outra obra sustentável é a requalificação da Avenida Comendador Franco, mais conhecida como Avenida das Torres, terá a inclusão de 10 quilômetros de ciclovias dentro do projeto de adequação da cidade para a Copa do Mundo de 2014. A ciclovia perpassará os dois lados da avenida, com sentidos opostos, totalizando 20 quilômetros de infraestrutura cicloviária.

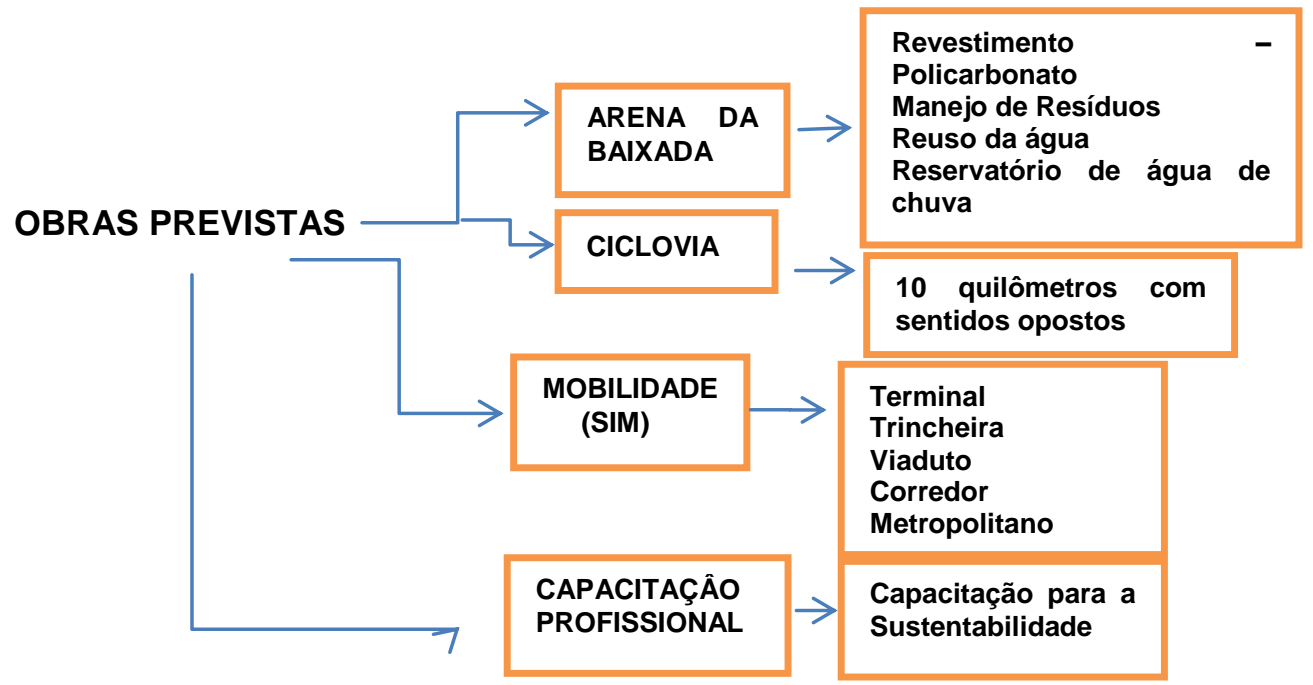


Acima, estão citadas as obras sustentáveis previstas como otimizadoras da Copa 2014 e o que as torna relevantes, em termos de sustentabilidade são a possibilidade de reduzir os impactos negativos e maximizar os impactos positivos. Na perspectiva sustentável importa o equilíbrio entre os aspectos econômicos, o desenvolvimento social e a proteção do meio ambiente, buscando um legado ambiental de longo prazo, capaz de inserir crescimento econômico, inclusão social e compromisso com o meio ambiente. As obras contemplam: estádio verde (certificado), manejo de resíduos, redução e compensação das emissões de carbono, energias renováveis, mudanças climáticas e desenvolvimento de capacidades. Detalhando o Sistema Integrado de Mobilidade (SIM), pode-se destacar a reforma e ampliação do terminal Santa Cândida, a trincheira da rua Guabirotuba, além do viaduto da Av. das Torres. Já, no Corredor Metropolitano faz-se relevante a interligação dos municípios de Curitiba, Almirante Tamandaré, Pinhais, Colombo, Piraquara, são José dos Pinhais, fazenda Rio Grande a Araucária, em trecho de 52 quilômetros. No âmbito social dá-se visibilidade à capacitação profissional para a sustentabilidade realizada pelo SEMA, IAP, COMEC, Instituto das Águas, UTFPR, SMMA, IPD, Casa Militar, ALEP e Câmara Mundial (PORTAL DA COPA, 2012).

\section{Considerações Finais}

O Brasil, ao realizar a Copa 2014 como um evento sustentável busca minimizar possíveis impactos negativos que possam vir a ser causados ao meio ambiente durante a execução das obras de grande porte. Busca-se a redução de custos e a maximização dos benefícios, tanto em aspectos de marketing de imagem do país como no reconhecimento de uma gestão de qualidade, corporativa, colaborativa e responsável.

Em relação à estruturação, gestão, impactos e legados de grandes eventos, o Brasil decidiu investir nesse campo, que considera um celeiro de oportunidades e desafios. Esses eventos se iniciam com a Cúpula das Nações Unidas Sobre Desenvolvimento Sustentável que ocorrerá em junho de 2012 no Rio de Janeiro, a (Rio+20). Segue: a Copa das Confederações em 2013, a Copa do Mundo de Futebol em 2014 e, as Olimpíadas no Rio de Janeiro em 2016.

$\mathrm{Na}$ esfera político-ambiental, esta é uma década palco de decisões fundamentais no que tange a relação com um novo regime global de mudanças climáticas, com o estabelecimento de diretrizes e metas de redução de emissões de GEE (BRASIL, 2005), destacam-se um novo sistema climático global e numa nova fase dos compromissos do Protocolo de Quioto, a partir do que for estabelecido no foro internacional para os próximos dois anos (ONU, 2005).

Para que um empreendimento seja considerado sustentável importa analisar se ele é ecologicamente correto, permeado por justiça social, economicamente viável e bem aceito culturalmente. As variáveis socioeconômicas precisam estar inseridas nas soluções tecnológicas. Portanto, importa analisar se a Copa 2014 está se configurando e/ou será sustentável, na abrangência das políticas públicas. Vale observar, para isso, se, passados os eventos, os grandes estádios construídos de forma 
sustentável possibilitarão a continuidade do exercício da função social, através de seu uso pela comunidade, bem como a continuidade do latejo econômico.

Embasado nesses pressupostos conceituais, a cidade de Curitiba Paraná - Brasil, localizada na região sul do país, pode melhor preparar-se para ser uma das cidades-sede da Copa de 2014, busca uma melhoria nos seus setores vitais para a economia. Além da visibilidade, Curitiba, pretende beneficiar-se com a dinâmica econômica obtida com investimentos e o grande fluxo turístico, melhorar setores que são vitais à economia, impulsionando, assim, o desenvolvimento municipal e regional. O trabalho, em sua segunda fase, buscará a formação do conceito de construção sustentável no recorte da Copa 2014, identificando os arranjos, os agentes, e as atuações no megaevento. Buscando apresentar as aplicações sustentáveis, através da análise das novas tecnologias sustentáveis e se contribuem para a mudança de valores, considerando sua assimilação no megaevento Copa 2014 de valores que consubstanciando em novas práticas.

\section{Referências}

BELLEN, H.M. Indicadores de Sustentabilidade: uma análise comparativa. FGV Editora, Rio de Janeiro, 2005.

BARBIERI, José Carlos. Organizações inovadoras sustentáveis. In: BARBIERI, J.C; SIMANTOB, M. Organizações inovadoras sustentáveis: uma reflexão sobre o futuro das organizações. São Paulo, Atlas, 2007.

CASAGRANDE JR, Eloy Fassi. Inovação Tecnológica \& Sustentabilidade: o Futuro da Construção da Construção Civil. UTFPR: Florianópolis, Set, 2011.

EcoDesenvolvimento.org. Iniciativas sustentáveis na construção das arenas da Copa do Mundo de 2014. Disponível em: http://www.ecodesenvolvimento.org.br/posts/2012/maio/iniciativassustentaveis-na-construcao-das-arenas\#ixzz205aPM69k ERNST; YOUNG. Brasil sustentável: Impactos Socioeconômicos da Copa do Mundo de 2014. EYGM Limited, 2010.

FREY, K. Políticas Públicas: um debate conceitual e reflexões referentes à prática da análise de políticas públicas no Brasil. Planejamento e Políticas Públicas, $\mathrm{n}^{\circ} 21$ - Jun, 2000.

FLORIDA, R. A Ascenção da Classe Criativa. Trad. Ana Luiza Lopes. Porto Alegre, RS: L\&PM, 2011.

FROTA, Anésia Barros; SCHIFFER, Sueli Ramos. Manual de conforto térmico. São Paulo: Studio Nobel, 1999. 3ed. 
FUNDAÇÃO GETULIO VARGAS (FGV). Propostas empresariais de políticas públicas para uma economia de baixo carbono no Brasil energia, transportes e agropecuária. Centro de Estudos em Sustentabilidade da Fundação Getulio Vargas - GVces. São Paulo, 2010.

FUSSEY, Pete; CLAVELL, Gemma Galdan. Introduction: toward's new frontiers in the study of mega-events and the city. URBE. Revista Brasileira de Gestão Urbana. (Brazilian Journal of Urban Management) v. 3, n. 2, p. 149-155, jul./dez. 2011.

GELINSKI, C.R.O; SEIBEL, E.J. Formulação de Políticas Públicas: questões metodológicas relevantes. Revista de Ciências Humanas. Florianópolis, EDUFSC, v. 42, № 1 e 2, p. 227-240, Abril e Outubro de 2008.

GIAMBIAGI, F; ALÉM, A. Finanças Públicas: Teoria e Prática no Brasil. Rio de Janeiro. Editora Campus/Elsevier, 2011.

GUEDES, et al. Copa 2014 - O estádio do Mineirão e Diretrizes de Sustentabilidade na Primeira Copa Verde do Mundo. UFMG/Escola de Arquitetura. Programa de Pós-graduação em Ambiente Construído e Patrimônio Sustentável, 2011.

JIMÉNEZ HERRERO, L. M. Desarrollo sostenible transición hacia la covolución global. 2. Ed. Madrid: Pirámid, 2000.

LANGONE, Cláudio. Copa do Mundo FIFA 2014-Agenda de Sustentabilidade e Meio Ambiente. Ministério do Esporte, 2011.

LEED. Reference Guide for Green Buildings' Design and Construction2009.

MARTINS, G.A.; THEÓPHILO, C. R. Metodologia da investigação científica para ciências sociais aplicadas. 2. Ed. São Paulo: Atlas, 2007.

MUSGRAVE, James. Event management and sustainability. Reino Unido, 2009.

PORTAL DA COPA, 2012. Painel discute a Copa como promotora de inovação e sustentabilidade. Disponível em: www.copa2014.gov.br. Acessado em 09/07/2012.

RESENDE, F. Poluição atmosférica por emissão de material particulado: avaliação e controle nos canteiros de obras de edifícios. Dissertação mestrado. Escola Politécnica da Universidade de São Paulo.2007. Disponível em: http://www.pcc.usp.br/fcardoso/Disserta\%C3\%A7\%C3\%A30\%20Fernando\% 20Resende\%20p\%C3\%B3s-banca\%202.pdf > Acesso em 02 Maio 2012. 
SILVA, C.L.; CASTRO R.F. Avaliação de Políticas Públicas para o Desenvolvimento Sustentável: um Estudo de Caso dos Programas de Educação de Curitiba de 1998 a 2005. Colombia Semestre Económico, vol. 12, núm. 23, enero-junio, Universidade de Medellin, 2009, pp. 77-96. 